\title{
Pioneering International Collaboration in Medical Education: The Ottawa-Shanghai Joint School of Medicine (OSJSM) Student Builder Program (SBP)
}

\author{
Chelsea Soares, $\mathrm{BHSc}^{1}$, Jason $\mathrm{Hu}, \mathrm{BSc}^{1}$, Kyle $\mathrm{Ng}, \mathrm{BSc}^{1}$, Fan Yang, $\mathrm{BHSc}^{1}$
}

${ }^{1}$ Faculty of Medicine, University of Ottawa

A B STR A C T

Shanghai is one of the world's fastest growing megacities. With a population of 24 million, it is clear that there is a huge demand for healthcare services. With the establishment of the first Canadian-International medical school, Ottawa-Shanghai Joint School of Medicine (OSJSM), four Student Builders were chosen to pilot clinical learning at Shanghai Jiao Tong University (SJTU) affiliated hospitals. Students were given opportunities to learn about the healthcare system in Shanghai, to work closely with medical students and physicians, to complete pre-clerkship observerships, and to be immersed in Chinese culture. The ongoing purpose of the Student Builder Program (SBP) is to evaluate the feasibility of having comprehensive undergraduate medical student engagement between the two cities. Students spent over 3 months in clinical settings with SJTU affiliated hospitals. Additionally, students worked closely with the OSJSM Student Affairs Office (SAO), delivered a presentation about Ottawa's medical curriculum to SJTU faculty, as well as conducted clinical research. To gain a deeper understanding of Chinese healthcare, students also had the opportunity to take a one-month Traditional Chinese Medicine (TCM) course. As a result, the Canadian medical students became familiarized with the Chinese healthcare system and culture, in addition to expanding their knowledge in medicine. This experience also provided the students with an opportunity to work with a large volume of patients. Moreover, the physicians at SJTU affiliated hospitals (primarily Renji Hospital) were able to gain a deeper understanding of University of Ottawa's medical school curriculum and clinical teaching methods.

\section{RÉ S U M É}

Shanghai est une mégapole connaissant une des croissances les plus rapides. Avec une population de 24 millions de personnes, il est clair qu'il y existe une demande soutenue de services de soins de santé. À la suite de la fondation de la première école de médecine canadienne internationale, soit l'École conjointe de médecine Ottawa-Shanghai (ECMOS), quatre étudiants « bâtisseurs » ont été sélectionnés pour être les premiers à explorer l'enseignement clinique offert dans les hôpitaux affiliés à l'Université Jiao Tong de Shanghai (UJTS). Les étudiants ont eu la possibilité d'en apprendre plus au sujet du système de soins de santé à Shanghai, de travailler en étroite collaboration avec des étudiants en médecine et des médecins, de compléter des stages observatoires du préexternat, et de s'immerger dans la culture chinoise. L'objectif du programme des étudiants-bâtisseurs, qui persiste à ce jour, est d'évaluer la possibilité d'établir un partenariat complet entre les deux villes, dont bénéficieraient les étudiants de premier cycle en médecine. Les étudiants ont passé plus de trois mois en milieu clinique dans les hôpitaux affiliés à la UJTS. En outre, ils ont travaillé de près avec le Bureau des services aux étudiants du ECMOS, ont présenté le curriculum médical d’Ottawa à la faculté de la SJTU, et ont effectué de la recherche clinique. Afin d'approfondir leur compréhension des soins de santé chinois, les étudiants ont aussi eu l'occasion de suivre un cours de médecine chinoise traditionnelle pendant un mois. Par conséquent, les étudiants en médecine canadiens se sont familiarisés avec le système de soins de santé chinois et la culture chinoise, en plus d'avoir acquis de nouvelles connaissances médicales. Cette expérience a aussi permis aux étudiants de travailler avec un grand nombre de patients. De surcroît, les médecins des hôpitaux affiliés à la UJTS (principalement l’hôpital Renji) ont pu développer une meilleure compréhension du curriculum médical à l'Université d'Ottawa et de ses méthodes d'enseignement clinique.

\section{INTRODUCTION}

As the world becomes increasingly globalized, medical schools are looking for ways to create programs and partnerships that reflect changes in the global landscape through a process known as internationalization [1]. The internationalization of medical schools and their curriculums present many challenges but also opportunities for students and faculty to mutually advance the Keywords: Shanghai; Electives; OSJSM; Jiao Tong University; UOttawa; Student Builder medical learning experience in addition to promoting global citizenship [1,2].

The relationship between Ottawa and Shanghai began in 2011 when Shanghai Jiao Tong University (SJTU), the University of Ottawa, and their affiliated hospitals collaborated on medical research projects. With the signing of the Memorandum of Agreement in October 2013 and both schools' commitment to 
innovating medical education, the idea of a joint school of medicine was born. It was not until March 2014 when the new Memorandum of Agreement was signed that the idea of a joint medical school began to turn into a reality with the development of the undergraduate medical education program [3].

With the establishment of the Ottawa-Shanghai Joint School of Medicine (OSJSM), four pre-clerkship Student Builders from the University of Ottawa piloted clinical observerships, worked closely with medical students and physicians, and immersed themselves in Chinese culture and healthcare systems.

The OSJSM Student Builder Program (SBP) serves to foster more comprehensive undergraduate medical student engagement between the two cities. The purpose of this study was to under- stand the challenges of completing international medical electives, such as when students do not speak the native language. In addition, students sought to understand the differences in the quality and quantity of education to be gained in Shanghai compared to Canada. This study wishes to determine the feasibility of electives in Shanghai and to further emerging opportunities for Undergraduate Medical Education (UGME) students.

\section{METHODS}

Four pre-clerkship medical students were chosen (of whom three had completed year one, and one had completed year two), and each student's summer studentship varied in composition. As outlined in Figure 1, their work was comprised of the following: exposure to several departments at SJTU affiliated hospitals

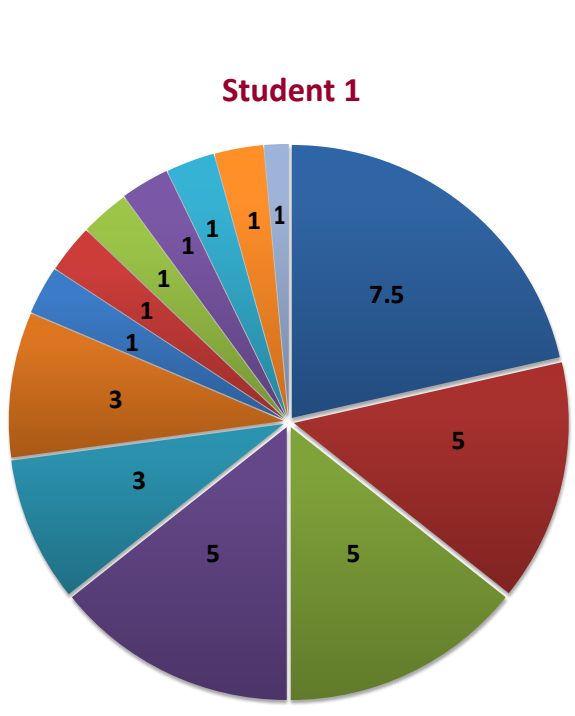

- General Practice

Emergency

neriatrics

Family Medicine Research

- Curriculum Development

Psychiatry

- Ob/Gyn

Hepatic Surgery

Urology

- Gastroenterology

- Cardiology

- Pediatrics

- TraditionalChinese MedicineClinic
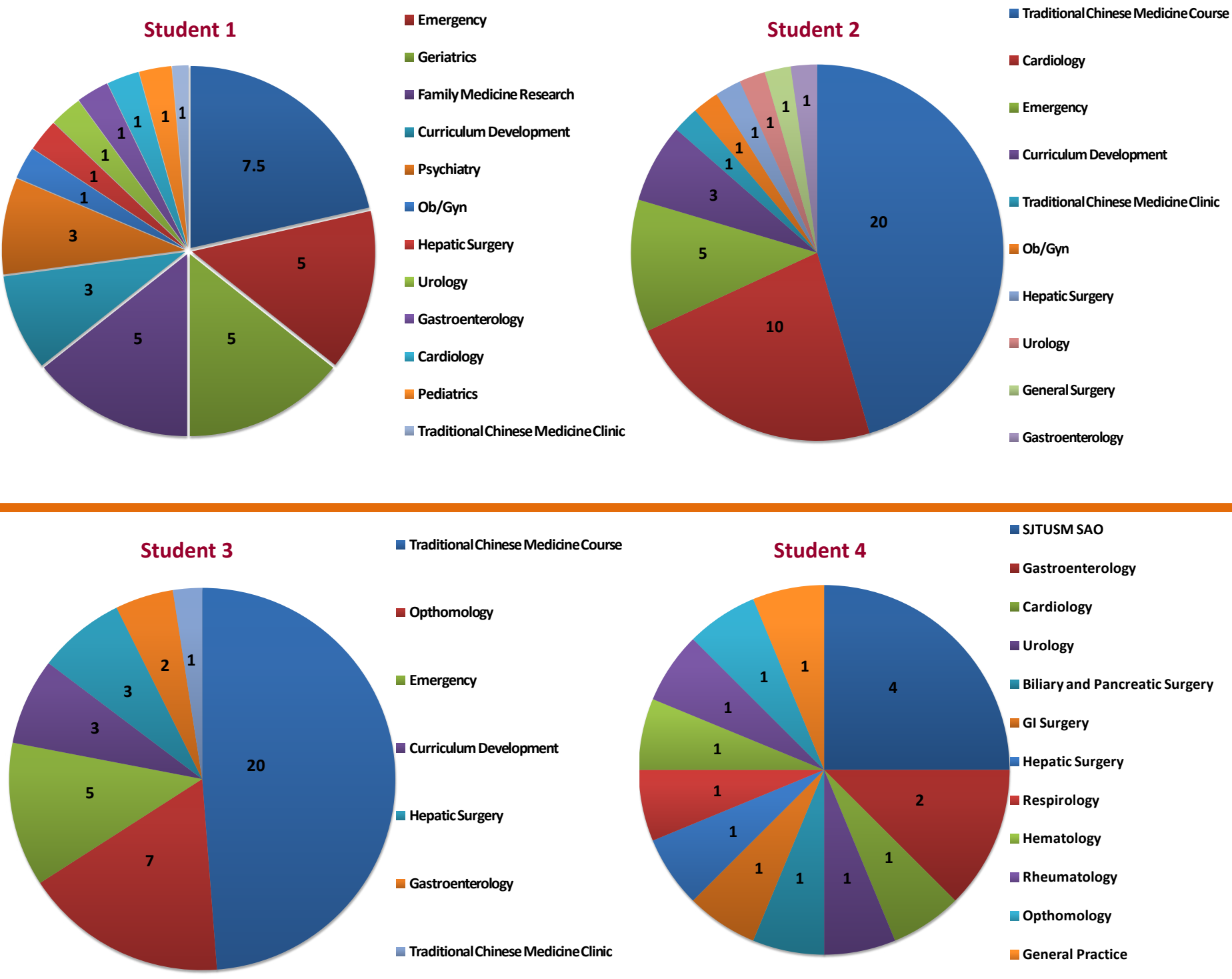

Figure 1: Days spent completing electives for each of the four participants during their summer studentships. 
(mainly at Renji hospital), work with the OSJSM Student Affairs Office (SAO), delivery of a presentation about Ottawa's medical curriculum to Shanghai faculty, participation in a one-month Traditional Chinese Medicine (TCM) course at Shanghai University of Traditional Chinese Medicine, and clinical research in Family Medicine.

Students chose electives based on specialties that Renji Hospital recommended and the individual student's interests. Amount of time spent in each specialty varied from a day to a few weeks depending on student preference. Electives were evaluated to see whether or not they were beneficial for pre-clerkship medical students based on fundamental objectives of any elective: learning the day-to-day lifestyle of physicians in a particular specialty, recognizing the common pathologies of that specialty, and practicing clinical skills (including history taking and physical examination skills). Of interest was the extent that the inherent language barrier and cultural differences had on the learning experience. In terms of collaborating with the OSJSM SAO, focus group discussions, class auditing, and questionnaires were used to understand the SJTU medical education system from the perspective of pre-clerkship students. The SJTU provided significant administrative support to facilitate the observational and focus group discussions. All student interactions were confidential. Information gathered from the students and staff was analyzed and utilized to guide future development of the OSJSM.

Another objective of this studentship was to share the University of Ottawa Faculty of Medicine's pre-clerkship curriculum with the Shanghai faculty, which was achieved through an oral presentation with the aid of a PowerPoint slideshow by JBH, CS and KN. $\mathrm{JBH}$ and CS took the opportunity to attend a TCM summer course at the Shanghai University of Traditional Chinese Medicine to better understand an integral part of medicine practiced in China.

Finally, an ongoing clinical research project was undertaken to better understand the primary care needs and perspectives of Shanghai patients in community health centers and tertiary care centers. $\mathrm{KN}$ undertook this project in partnership with the staff at the Office of Internationalization and under the supervision of Dr. Dianne Delva (Chair of Family Medicine at University of Ottawa) and Dr. Chao Meng (Professor of Geriatric Medicine at Renji Hospital). A 20-question survey was administered to 400 patients at 2 community health centers and at Renji Hospital, and currently remains in the analysis phase.

\section{RESULTS}

All in all, the Shanghai SBP provided an added benefit above and beyond what might be expected in other international elective settings. The gross results include four elective evaluation reports, a Shanghai Medical Student Guide, a curriculum presenta- tion to OSJSM faculty, a Family Medicine clinical survey, and a submission to the Canadian Conference on Medical Education. This was made possible through the close working relationship with faculty, the support of administrative staff in Ottawa and Shanghai, and the openness of Shanghai partners.

These results can be broadly categorized into both advancing the medical education of Ottawa learners, as well as advancing clinical and faculty development in Shanghai. Current and future Student Builders bear the responsibility of explaining the pros and cons of doing an elective in Shanghai, as well as elaborating on daily survival tips in one of Asia's biggest megacities. These were fulfilled through elective evaluation reports and the Shanghai Medical Student Guide, respectively, which are both available through the Office of Internationalization upon request.

Through the bilateral nature of the SBP, students were also given the opportunity to provide feedback in the hopes of benefiting patients and future learners. This was done primarily through the presentation on Ottawa's medical curriculum, as well as feedback through elective reports. While the OSJSM professors were eager to hear about the strengths and benefits of a North American undergraduate medical education system, they were made aware of weaknesses in Ottawa's UGME curriculum. It may yet prove to be a long time before substantial changes are effected, but the hope is that ongoing bilateral exchanges, such as the SBP, will facilitate positive learning exchange for healthcare systems in Ottawa and Shanghai.

\section{Language}

One of the main concerns from the beginning was that the potential presence of a language barrier might hinder the learning experience. This was not the case in most respects. Most preceptors were strong English communicators and thus were able to teach concepts and summarize patient interactions in order for students to learn from patient encounters. In particular, because physicians took extra time to explain each encounter, students generally had more didactic learning during these electives than during electives in Ottawa. It should be mentioned that not all students had the opportunity to take patient histories because of the language barrier. Moreover, students were given procedural skill learning opportunities that would have been otherwise tougher to obtain during electives in Ottawa. For example, a student was taught how to use the slit lamp and was allowed to practice with a medical student from SJTU.

\section{Clinical Learning Advantages}

There were many clinical advantages to completing an elective in Shanghai (Table 1). Firstly, completing an elective in a large tertiary hospital allowed students to be exposed to a higher patient volume and greater disease variety than in Ottawa. This created 
Table 1: Comparison of students' pre-clerkship electives in Shanghai versus Ottawa in various medical fields

\begin{tabular}{|c|c|c|}
\hline Specialty & Shanghai & Ottawa \\
\hline Ophthalmology & $\begin{array}{l}\text { Strengths: } \\
\text { - Able to observe in OR } \\
\text { - Direct access to staff physicians } \\
\text { - Learned how to use slit lamp } \\
\text { - Can be booked } 1 \text { week in advance } \\
\text { - Able to see imaging techniques } \\
\text { Weaknesses: } \\
\text { - Did not have teaching scopes } \\
\text { - Language barrier: doctor had to summarize } \\
\text { findings and interaction post-examination }\end{array}$ & $\begin{array}{l}\text { Strengths: } \\
\text { - Able to communicate with patient, follow } \\
\text { doctor-patient interaction } \\
\text { - Have teaching scope in } 1 \text { room } \\
\text { Weaknesses: } \\
\text { - Not allowed to observe in OR } \\
\text { - Shadowed residents } \\
\text { - Did not have the opportunity to learn slit lamp } \\
\text { - Must be booked months in advance } \\
\text { - Limited exposure to imaging }\end{array}$ \\
\hline Emergency & $\begin{array}{l}\text { Strength: } \\
\text { - High volume } \\
\text { - More available shifts in ER } \\
\text { Weaknesses: } \\
\text { - Little bedside teaching } \\
\text { - Less physician-patient interaction } \\
\text { - No student-patient interaction } \\
\text { - Poorly structured emergency system \& specialty } \\
\text { - Physicians not accustomed to teaching } \\
\text { international pre-clerkship students }\end{array}$ & $\begin{array}{l}\text { Strengths: } \\
\text { - High quality teaching } \\
\text { - One on one exposure to patients in } \\
\text { pre-clerkship } \\
\text { - Procedural learning (i.e. stitches) } \\
\text { - History/Physical with feedback } \\
\text { Weaknesses: } \\
\text { - Less volume } \\
\text { - Hard to find availability in } \mathrm{TOH} \text { emergency for } \\
\text { electives }\end{array}$ \\
\hline Cardiology & $\begin{array}{l}\text { Strengths: } \\
\text { - Observed PCl and PDA } \\
\text { - Observed cardiac care unit rounds } \\
\text { - Observed Treadmill tests } \\
\text { - Observed Echo lab } \\
\text { - Observed electrophysiology and ablation } \\
\text { - Observed cardiac MRI } \\
\text { Weaknesses: } \\
\text { - Did not take patient histories and conducted } \\
\text { minimal physical exams }\end{array}$ & $\begin{array}{l}\text { Strengths: } \\
\text { - Observed } \mathrm{PCl} \\
\text { - Observed cardiac care unit rounds } \\
\text { - Took patient histories and conducted physical } \\
\text { - exams in outpatient clinic } \\
\text { - Shadowed doctor } \\
\text { Weaknesses: } \\
\text { - Not enough exposure to outline significant } \\
\text { weaknesses }\end{array}$ \\
\hline General Practice & $\begin{array}{l}\text { Strengths: } \\
\text { - General practice exists in Community Health } \\
\text { Centers and Stations around Shanghai } \\
\text { - General practice emphasizes home visits, } \\
\text { prescription renewals, TCM } \\
\text { Weaknesses: } \\
\text { - General practice limited in scope by pharma- } \\
\text { ceutical distribution policy, by infection control } \\
\text { policy, by training, by practice limitations } \\
\text { - Minimal history or physical exams done by } \\
\text { physicians, even fewer by students }\end{array}$ & $\begin{array}{l}\text { Strengths: } \\
\text { - Family Medicine introduced very early in Medi- } \\
\text { cal school curriculum, mandatory exposure } \\
\text { - Family medicine wide ranging in scope, and self } \\
\text { regulated limits } \\
\text { - Students take patient histories, physical exams, } \\
\text { differential diagnoses done under supervision } \\
\text { by preceptors } \\
\text { Weaknesses: } \\
\text { - Preceptor dependent variable experience } \\
\text { - Lower volume of patients (though highly vari- } \\
\text { able across clinics) }\end{array}$ \\
\hline
\end{tabular}

\section{Abbreviations:}

OR: Operating Room

ER: Emergency Room

TOH: The Ottawa Hospital
PCl: Percutaneous Coronary Intervention PDA: Patent Ductus Arteriosus
MRI: Magnetic Resonance Imagin

TCM: Traditional Chinese Medicine 
more opportunities for students to learn and apply their knowledge. Another highlight of completing electives at Renji Hospital were the staff physicians, who were easily accessible, even with short notice, and were very enthusiastic about teaching. Physicians were eager to educate, to show students their specialty of medicine, and to provide them with unique opportunities including: cardiac MRI, TCM, scrubbing in during allogeneic liver transplant surgery, watching endoscopic sub-mucosal dissection, and watching ophthalmologic surgeries. When students observed surgeries or medical procedures, staff physicians generally erred on the side of caution, resulting in students facing less ethical concerns. Finally, completing electives in Shanghai allowed for cross-systems learning, as students were able to learn about the Chinese healthcare system and the staff physicians learned about the Canadian healthcare system. Primary care systems and specialist referrals were among the highlighted topics discussed, compared, and researched. Overall, students were able to acquire knowledge, apply core concepts learned in pre-clerkship, and observe a variety of procedures.

\section{Main Clinical Disadvantages}

On the other hand, in order to appreciate and provide care to patients from a completely different culture, one has to spend a significant amount of time living in Shanghai to be fully immersed in the culture. Not unlike most healthcare systems, Chinese healthcare is complex and requires a significant amount of time to appreciate how the healthcare system functions. This understanding would be a necessary pre-requisite to providing effective and culturally appropriate patient care. Therefore, the challenge for most Canadian medical students will be the amount of time that they can spend to be accustomed to the culture of healthcare. For instance, with the heavy patient volume, specialists only have 3 to 5 minutes with a patient and some specialists may see up to one hundred patients in a day. This phenomenon leads to a culture that is heavily reliant on laboratory and radiological testing, as opposed to extensive histories or physical examinations.

With the differences in medical education, Canadian clerkship and pre-clerkship students will be at a different level in terms of medical knowledge and expertise. Most preceptors were not accustomed to international pre-clerkship learners following them and the objectives associated with the observership. When informed about the students' current knowledge and objectives, preceptors then were tasked with facing this new situation and thus had varying levels of success in terms of providing teaching. This aspect will improve as time goes on since the preceptors are given feedback and they will have more experience with international leaners.

In terms of the elective experience, elective opportunities varied widely in effectiveness and quality, across departments and be- tween preceptors (Table 1). For instance, electives in Emergency Medicine and General Practice demonstrate that high patient volume can also compromise the quality of teaching as the staff physicians are struggling to meet the demand for healthcare. Preceptors in China are not familiar with pre-clerkship knowledge, which makes it challenging to address learning objectives, but this will improve over time with the development of the partnership.

\section{Traditional Chinese Medicine Course}

$\mathrm{JBH}$ and CS obtained certificates for completing the 4-week course from the Shanghai University of Traditional Chinese Medicine. The course was taught in English by Chinese physicians and consisted of didactic lectures, clinical workshops for acupuncture and tuina, cultural workshops and field trips, Taiji and Qi Gong, clinical exposure to TCM hospital wards, and Chinese language classes. Although only touching the surface of this complex field, this course shed light on a previously unfamiliar aspect that is an integral part of Chinese healthcare.

\section{DISCUSSION}

The SBP offers a unique and advantageous experience with cross-systems learning, high volume procedural learning, OSJSM curriculum development, research opportunities, and most importantly strong student-faculty partnership and post-program involvement when compared to pre-clerkship electives in Ottawa. Bedside teaching at select departments were very accessible in English and well organized, however other departments that were explored had room for pre-clerkship teaching development. However variable, participating students gained clinical and medical education research experience, gained cultural exposure, and furthered the Ottawa-Shanghai Joint Medical School curriculum and partnership development through evaluation facilitated by the first iteration of the SBP. In comparison to the organization of most ad hoc international placements, this elective allows for an unprecedented conversation between visiting and host faculties, as well as students (Figure 2). As the program moves forward, students and faculties involved will require additional evaluation for the improvement of future University of Ottawa elective opportunities, Shanghai clinical learning, and the development of the OSJSM.

\section{CONCLUSION}

Individually, each of the Student Builders was able to gain valuable clinical exposure and was challenged to approach healthcare in a culturally sensitive manner. Collectively, by collaborating with the students and faculty from both countries, valuable relationships and partnerships were built, which will enhance further student engagement in the OSJSM. From a societal per- 


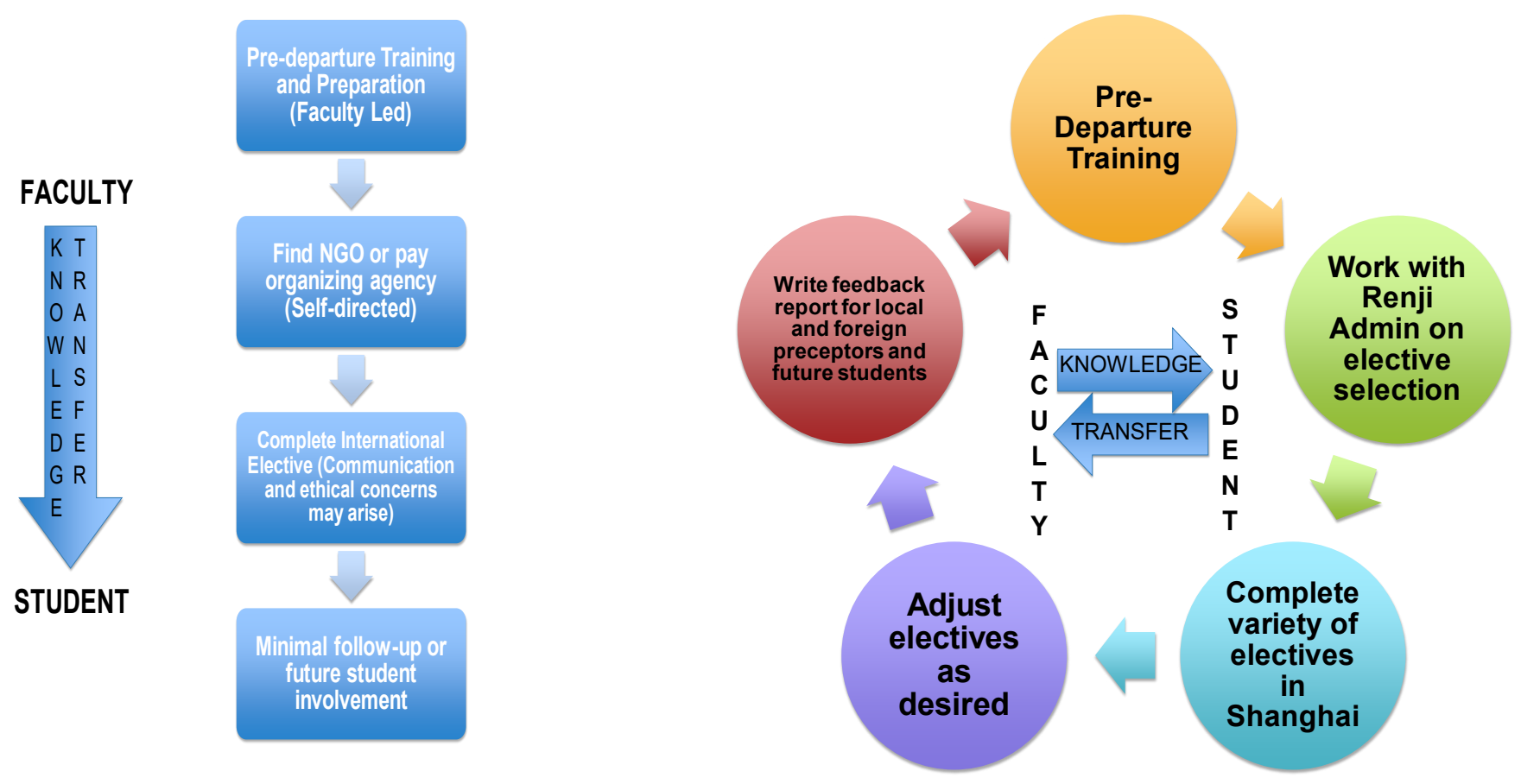

Figure 2: Comparison of ad hoc international electives and Renji Hospital organized electives.

spective, this OSJSM partnership provides an integrated faculty model for Canadian medical schools that mutually and sustainably shares medical knowledge, resources, and education methods globally.

\section{ACKNOWLEDGEMENTS}

We would like to thank the multitude of people who made our preparations in Ottawa, and our time in Shanghai, possible. Drs. Yuwei Wang, Jonathan Gendron, Nathalie Pellerin-Tessier, Jing Jing Chen, all the staff of the Office of Internationalization, and especially Dr. Yi Li at Renji Hospital were instrumental in their tremendous support.

\section{REFERENCES}

1. Hansons L. Global Citizenship, Global Health, and the Internationalization of Curriculum: A Study of Transformative Potential. Journal of Studies in International Education. 2010;14(1), 70-88.

2. Harden RM. International medical education and future directions: a global perspective. Acad Med. 2006;81(12 Suppl), S22-29.

3. Ottawa Shanghai Joint School of Medicine. History of the Joint School [Internet]. Ottawa (ON): University of Ottawa, Department of Medicine; [cited 2016 Jan 2]. Available from: http://med.uottawa.ca/joint-school/about-us/ history-joint-school. 